\title{
Streptococcal toxic shock syndrome: A rare case in a child with an unusual presentation
}

\author{
P Kariyawasam ${ }^{1}$, W A N D Wickramasinghe ${ }^{2}$, *N D Liyanarachchi ${ }^{3}$, P Gamage $^{4}$, J Liyanage $^{5}$
}

Sri Lanka Journal of Child Health, 2019; 49(1): 85-86

DOI: http://dx.doi.org/10.4038/sljch.v49i1.8908

(Key words: Streptococcal septic shock syndrome, child, necrotising fasciitis)

\section{Introduction}

The incidence of invasive streptococcal infection is continuing to rise significantly since the 1980 s, according to many studies ${ }^{1}$. Showing a very high mortality in the range of $30-70 \%$ even with modern, aggressive management strategies, streptococcal toxic shock syndrome (STSS) has a grim prognosis compared to its counterpart, staphylococcal toxic shock syndrome ${ }^{1}$. The case definition of STSS is shown in Box 1.

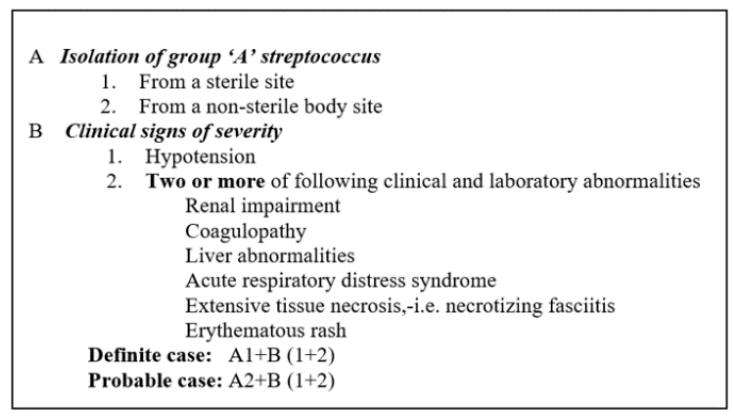

Box 1: Case definition of streptococcal toxic shock syndrome ${ }^{1}$

Here we describe a child who developed STSS due to necrotizing fasciitis and unfortunately succumbed despite intensive medical care.

\section{Case report}

A 12 year old previously healthy boy was admitted with sudden onset back pain of a few hours duration. He had gone to school without any complaint that

\footnotetext{
${ }^{1}$ Registrar in Paediatrics, ${ }^{2}$ Senior Registrar in Paediatrics, ${ }^{3}$ Senior Lecturer and Consultant Paediatrician, Professorial Paediatric Unit, Teaching Hospital Karapitiya, Sri Lanka. ${ }^{4}$ Paediatric Intensivist, Paediatric Intensive Care Unit, ${ }^{5}$ Consultant Paediatric Surgeon, Teaching Hospital .Karapitiya. Sri Lanka

*Correspondence: liyanarachchiuk@yahoo.co.uk
}

(iD) https://orcid.org/0000-0003-3920-8653

(Received on 13 June 2018: Accepted after revision on 20 July 2018)

The authors declare that there are no conflicts of interest

Personal funding was used for the project.

Open Access Article published under the

Commons Attribution CC-BY (c) (i) License morning, but during the afternoon, the school authorities informed parents about the back pain. He did not give a preceding history of trauma but admitted engaging in vigorous play activities like climbing trees during the week prior to admission.

On admission, he was afebrile and the rest of the physical examination was normal. Initial investigations revealed a white blood cell (WBC) count of 3100 with $90 \%$ neutrophils, and an erythrocyte sedimentation rate (ESR) of $20 \mathrm{~mm} / 1 \mathrm{st}$ hour. X-rays of the lumbosacral spine and pelvis were normal.

About 18 hours after admission, the pain got worse and it was not relieved after giving a single dose of a non-steroidal anti-inflammatory drug (NSAID). He complained of severe pain radiating along the right leg. He still did not have fever and the cardiovascular status was normal except for tachycardia. Rheumatology and orthopaedic opinions were obtained and did not point towards any specific abnormality. Ultrasound scan of the abdomen was normal. The C-reactive protein (CRP) was high $[55 \mathrm{mg} / \mathrm{dl}]$ and the blood picture showed evidence of bacterial infection. Following day, he had fever, looked more ill and had reduced urine output. The serum creatinine and liver enzymes were elevated. Treatment commenced urgently as for possible sepsis with broad spectrum antibiotics, but the child deteriorated over the next few hours with hypotension, oliguria, altered consciousness, distended tender abdomen, respiratory distress and high lactate levels. After stabilizing with oxygen and fluid boluses, he was transferred to the paediatric intensive care unit (PICU).

Eventually, he was ventilated and commenced on inotropes. Second ultrasound scan of the abdomen demonstrated free fluid localized in the right iliac fossa. Contrast computed tomography (CCT), which was performed in collaboration with the paediatric surgical team, showed inflammation of right ilium and appendix and free fluid. Subsequent laparoscopic examination revealed a moderate amount of blood stained, thick fluid and inflammation of peritoneum over the right iliac fossa, suggestive of necrotizing fasciitis. The blood culture yielded group 'A' streptococcus which confirmed the diagnosis of STSS, but the tissue fluid 
was sterile. Despite vigorous management with high grade antibiotics and intravenous immunoglobulin, the child passed away on the fourth day after PICU admission.

\section{Discussion \\ STSS occurs due to invasive group 'A' beta haemolytic streptococcal infections, mainly streptococcus pyogenes ${ }^{2}$. The acquisition of these virulent organisms in STSS is known to occur in a variety of ways such as penetrating or non- penetrating trauma and minor surgical procedures ${ }^{1}$. Rarely, even streptococcal pharyngitis has been identified as a possible aetiology ${ }^{1}$. Certain viruses like varicella and influenza can provide a portal of entry while non-steroidal anti-inflammatory drugs may expedite the progression ${ }^{1}$.}

The association between STSS and necrotizing fasciitis has been recognized since a long time ${ }^{1,3}$. In such sites of inflammation, the invasive beta haemolytic streptococci have several $\mathrm{M}$ proteins [M $1,3,12,28]$ anchored to their cell membranes which have anti-phagocytic properties and, these in turn, are associated with increased toxin production, shock and multi-organ dysfunction ${ }^{1}$. An important product called pyrogenic exotoxin ' $A$ ' acts as a super antigen and induces proliferation of $T$ lymphocytes and monocytes which produce lymphokines and monokines in a watershed manner, contributing to the pathogenesis of shock ${ }^{1}$.

Although not quite evident at first, retrospectively, our patient fulfilled almost all the criteria of STSS (Box 1). All patients develop shock within a few hours after the onset of the disease which may persist for a while before the full blown clinical features appear ${ }^{1}$. Most may present with fever ${ }^{1}$. Pain is typically present before the onset of other features of infection or shock ${ }^{1}$. Pain may represent soft tissue of an extremity or can mimic acute surgical conditions of abdomen and pelvis ${ }^{1}$.

Complications of STSS include bacteraemia, renal failure, acute respiratory distress syndrome (ARDS), and disseminated intravascular coagulation $^{1}$. Penicillin group beta lactam antibiotics with clindamycin are considered as effective antimicrobials in many centres while providing optimum organ support as required ${ }^{1}$. Urgent surgical debridement or amputation might be essential in certain patients to avoid fatal outcome ${ }^{1}$. Intravenous immunoglobulin is coming up as a novel treatment option according to a few recent studies conducted by certain centres and is thought to act by neutralizing bacterial toxins ${ }^{4}$.

We conclude that STSS can present with unusual localized pain syndromes with or without shock, requiring a high degree of clinical suspicion for early diagnosis. It is important to provide optimum multimodal care to prevent the rapid progression to death. More importantly, any child who presents with unusual complaints needs critical analysis of symptoms and signs and timely intervention.

\section{References}

1. Stevens DL. Streptococcal toxic-shock syndrome: Spectrum of disease, pathogenesis, and new concepts in treatment. Emerging Infectious Diseases 1995; 1(3): 69-78.

https://doi.org/10.3201/eid0103.950301

PMid: 8903167 PMCid: PMC2626872

2. Centers for Disease Control and Prevention's (CDC) National Notifiable Diseases Surveillance System (NNDSS) and Case Definitions. http://wwwn.cdc.gov/nndss/conditions/str eptococcal-toxic-shocksyndrome/casedefinition/2010/ (2/16).

3. Stevens DL, Tanner MH, Winship J, Swarts R, Ries KM, et al. Severe group A streptococcal infections associated with a toxic shock-like syndrome and scarlet fever toxin A. New England Journal of Medicine 1989; 321(1):1-7 https://doi.org/10.1056/NEJM1989070632 10101

PMid: 2659990

4. Darenberg J, Ihendyane N, Sjolin J, Aufwerber E, Haidl S, Follin P, et al, Intravenous immunoglobulin $G$ therapy in streptococcal toxic shock syndrome: A European randomized, double-blind, placebo-controlled trial. Clinical Infectious Diseases 2003; 37(3):333-40. https://doi.org/10.1086/376630

PMid: 12884156 